$\xi=-1$ 圆

\title{
Comparative study of different alloys during thermal debind-ing of powder injection molded parts
}

\author{
W.H. El-Garaihy ${ }^{1 *}$, Ahmed Nassef ${ }^{2}$, Medhat El-Hadek ${ }^{2}$ \\ ${ }^{1}$ Mechanical Engineering Department, Unayzah College of Engineering, Qassim University, Kingdom of Saudi Arabia On leave from: \\ Mechanical Engineering Department, Faculty of Engineering, Suez Canal University. Egypt \\ ${ }^{2}$ Port-Said University, Department of Production \& Mechanical Design, Faculty of Engineering, Port-Said, Egypt. \\ *Corresponding author E-mail:
}

\begin{abstract}
Powder injection molding (PIM) is an interesting technique and address of research, in which a thermoplastic polymeric material is used to form the powder into the desired shape in a closed die. Binders have a crucial importance in the powder metallurgy technology as they play a vital role to provide efficient powder agglomeration and/or lubrication during shaping. At the same time, they have to be easily removed from the compacts during initial stages of sintering, using debinding process, without any damaging effect for the base material. Thermal debinding is a vital process requiring somewhat elevated temperatures to remove binder from the compact. In the current study, an investigation has been made about the effect of process variables on the debinding of injection molded pieces, by melt wicking. The debinding process was performed at temperatures ranging from 160 - up to- $200^{\circ} \mathrm{C}$ for a time duration varying from 1 -up to- 27 hours. All powders used in injection molding feedstock have an inherent packing porosity. Several types of alloy powders (Carbonyl iron steel, Nickel aluminide, and 316L stainless powders), with various size distributions, particle shapes, and materials are adopted to define the influence on binder incorporation resulted from this inherent porosity. Results revealed that the increase of debinding time or decrease in the wicking powder (alumina) particle size lead to an increase in the thickness of the adhered layer of alumina. When the wicking powder is very fine $(0.3 \mu \mathrm{m})$ or has a wide particle size range $(<10 \mu \mathrm{m})$, it becomes more dense and its debinding efficiency is decreased. At high debinding temperatures $\left(200{ }^{\circ} \mathrm{C}\right)$ the rate of binder evaporation and removal increased, which leads to decreasing the cohesion of the samples yielding a shape distortion. In addition, the effect of the wicking powder $\left(\mathrm{Al}_{2} \mathrm{O}_{3}\right)$ sizes and debinding time on the binder weight loss percentage after debinding process for $\mathrm{FeOX}, \mathrm{Ni}_{3} \mathrm{Al}$, and $316 \mathrm{~L}$ has been investigated.
\end{abstract}

Keywords: Capillary Flow; Powder Injection Molding; Thermal Debinding; Thermal Wicking.

\section{Introduction}

Main advancements in powder processing dealing with particulate materials are correlated with the potential growth in their shape complexity and performance levels. Binder-assisted forming techniques are considered, nowadays, an important potential address of research in the area of powder processing. One of the most important techniques is the powder injection molding (PIM), which is based on using a closed die to form the powder into a desired shape using a thermoplastic polymeric material [1-3]; therefore, it is a combination of conventional plastic molding and powder metallurgy, which benefits from each in easy shaping and superior mechanical properties, respectively [4-5]. PIM, as a forming technique for high temperature alloys, has been paid great attention due to its high potential for producing complex shapes with large quantities and at low cost [6]. PIM has several steps beginning with the mix of metal powder with a polymer, followed by molding the mixed feedstock into shaped parts, going to removing the polymer, and finally the sintering process which aims at densifying the powder and removing most of the void space left by the binders [7-8].

The compact obtained, after PIM process, consists of solid particles held together by binder phase, without pores, where solid particles are in point contact and the binder forms a continuous network throughout the compact. Consequently, an extrusion for the binder must take place, without the distortion or pollution of the compact, prior to the sintering process [6]. This removal, which is called debinding, could be done using treatments by chemicals (solvents) and thermal routes [9-10]. Subsequently, a sintering process is done for the porous products to a density near the theoretical required one.

Debinding is a critical core step in eliminating large fraction of the organic phase, in which defects such as cracking, bloating, or deforming is avoided [11-12]. Thermal debinding is the first and the most common utilized method in the PIM industry, due to its simplicity and low equipment investment. During this process, decomposition takes place, at first, for some binder components at low temperatures leaving pore channels behind. Consequently, the pore network is formed and parts are further heated to pyrolyze high molecular weight polymers. Important measures, of binder removal rate and the compact condition after debinding, are dependent on the complex interaction between the pore structure of the compact, binder chemistry, debinding conditions, processing cycle, temperature, time, and particle size of the wicking powder [12-15]. The wicking powder decreases the total debinding time, where wicking starts to get rid of the binder at a low temperature; at which, there are less distortion and thermal stresses; therefore, decreasing the damage chance of compact.

During thermal debinding, the component strength decreases, at first, due to thermal softening of the polymer; consequently, polymer loss. Likewise, stresses (thermal, gravitational, residual, and 
other resulted from trapped gases due to polymer degradation) affect the component, which could lead to cracks or distortion as the polymer degrades. Other than these macroscopic defects, any microscopic defect caused during thermal debinding is increased noticeably during subsequent sintering. Therefore, the saying that sintering helps in minimizing defects is absolutely wrong and the total opposite is the actual case. Consequently, non-optimal selection of process conditions could lead to unwanted results [16].

The aim of this study is to investigate the influence of process variables on the debinding of injection molded pieces by melt wicking; where thermal wicking (capillary flow) is used to remove the binder. Carbonyl iron steel, Nickel aluminide, and 316L stainless powders are used in this study, which are known for their good mechanical properties, corrosion resistance, and behavior suitable for a wide range of applications [17].

\section{Materials and experimental procedure}

Different powder alloys are selected to study the thermal debinding process of injection molded parts. Two component binder systems were used to prepare the powder-binder feedstock consisting of low density polyethylene (PE 520) and ethylenebistearamide (WC). The theoretical mixture density is a linear function of the volume fraction of solids and could be represented by the following relationships [15], [17-18]:

$$
\begin{aligned}
& \phi=\left[1+\frac{\rho_{\mathrm{p}} \mathrm{w}_{\mathrm{b}}}{\rho_{\mathrm{b}} \mathrm{w}_{\mathrm{p}}}\right]^{-1} \\
& \rho_{t}=\frac{\rho_{p} \cdot \rho_{b}}{\rho_{b} X_{p}+\rho_{p} X_{b}} \\
& \phi_{c}=3.2-28.01 f_{p}+12.82 \varphi-6.89 \varphi^{2}+22.93 f_{p}^{2} \\
& \varphi=0.079+0.83 f_{p}+1.53 f_{p}^{3}
\end{aligned}
$$

Where: the subscripts $\mathrm{p}, \mathrm{b}$ denote the powder and the binder; respectively, $\phi$ is the volumetric loading of powder in the binder, $\rho$ is the solid density, $\rho \mathrm{t}$ is the density of the mixture, $w$ is the weight, $\mathrm{X}$ is the weight fraction, $\mathrm{f}$ is the fraction tap density, $\varphi \mathrm{c}$ is the critical solids loading, and $\varphi$ is the particle sphericity. The critical weight fraction of powder loading was calculated for the powder systems using Equations (1-4) and is presented in Table (1). The melting temperature and density of the binder used in this study are listed in Table (2).

The powders with the appropriate amount of binder (PE520 and WC) were mixed and blended by a mixer in a heated chamber at a temperature of $160^{\circ} \mathrm{C}$ for one hour. After mixing, the mixture was cooled down to room temperature and crushed, which served as the feedstock.

Table 1: The Materials and Binder Used.

\begin{tabular}{llll}
\multicolumn{3}{c}{ Table 1: The Materials and Binder Used. } \\
\hline $\begin{array}{llll}\text { Power Alloy } \\
\text { Type }\end{array}$ & \multicolumn{3}{c}{ Binder wt.\% } \\
$\mathrm{Ni}_{3} \mathrm{Al}(100-106 \mu \mathrm{m})$ & 95.5 & WC & PE520 \\
$\mathrm{FeOX}(3-4 \mu \mathrm{m})$ & 86 & 8.6 & 2 \\
316L $(22-44 \mu \mathrm{m})$ & 93.22 & 4.09 & 2.69 \\
\hline
\end{tabular}

Table 2: Binder Melting Temperatures and Densities.

\begin{tabular}{lll}
\hline Binder Type & $\operatorname{Tm}\left({ }^{\circ} \mathrm{C}\right)$ & $\rho(\mathrm{g} / \mathrm{cm} 3)$ \\
\hline PE 520 & 96 & 0.924 \\
WC & 144 & 0.927 \\
\hline
\end{tabular}

The dynamic viscosity $(\eta)$ is measured for each feedstock to determine the suitable pressure and temperature for the injection molding machine $[7,19]$. Too low temperature could lead to a denser viscosity that would result in an incomplete die fulfilment; On the other hand, too high temperature could lead to diluter viscosity that would induce the two-phase separation of powers and binders resulting in macroscopic crack and residual flash. Similarly, too high or low injection pressure may also bring defects for the molded compacts [20]. The effects of injection temperature and pressure on the shaping of molded compacts were studied and the optimum values were determined. Table (3) shows the suitable pressure and temperature of each feedstock for the different powder alloys. This feedstock was then transferred to an injection molding machine, where cylindrical bar specimens were prepared with diameters of $20 \mathrm{~mm}$ and $100 \mathrm{~mm}$ long. Mold samples were embedded in the aluminum oxide powder $\left(\mathrm{Al}_{2} \mathrm{O}_{3}\right)$ in a stainless steel container. Different particle sizes of wicking alumina powder of $0.3,1,<10,<30$, and 50-200 $\mu \mathrm{m}$ were used. The debinding was performed at a temperature range of 160 -up to- $200{ }^{\circ} \mathrm{C}$ for a time ranging from 1-up to-27 hours. Digital balance with $\pm 0.0001 \mathrm{~g}$ accuracy has been used to weigh each sample before and after debinding, to determine the weight loss due to the absorbing the binder by the wick.

Table 3: Pressure and Temperature of the Injection Molding Machine for Each Feedstock.

\begin{tabular}{lll}
\hline Material & $\mathrm{P}, \mathrm{MPa}$ & $\mathrm{T},{ }^{\circ} \mathrm{C}$ \\
\hline $\mathrm{Ni}_{3} \mathrm{Al}$ & 70 & 150 \\
$\mathrm{FeOX}$ & 25 & 155 \\
$316 \mathrm{~L}$ & 50 & 160 \\
\hline
\end{tabular}

\section{Results and discussion}

The binder removal is a very complicated process and depends on many variables. Such variables include the heating rate, temperature, and time. In addition, the type and the volume fraction of the binders; as well as, the particle size of the wicking powder had a significant influence on the binder removal process. Moreover, the rate of the binder removal from the green compact is different for each material and depends on its particle size.

Figs. 1 and 2 show the effect of alumina particle size on the thickness of adhered layer of alumina at the debinding temperature of $160{ }^{\circ} \mathrm{C}$ on the surface of $\mathrm{FeOX}$ and $316 \mathrm{~L}$ samples, respectively. From these figures it is clear that the increase of debinding time or decrease in the alumina particle size resulted in the increase in thickness of the adhered layer of alumina. Moreover, by observing Figs. 1 and 2, it could be realized that the wicking powder with particle sizes of 0.3 and $<10 \mu \mathrm{m}$ stick to the compact surface. Therefore, when the wicking powder is very small $(0.3 \mu \mathrm{m})$ or has a wide particle size range $(<10 \mu \mathrm{m})$, it becomes more dense and its debinding efficiency is decreased. This may give a chance for powder agglomeration and adherence to the compact surface.

As the temperature of the debinding process was increased to 200 ${ }^{\circ} \mathrm{C}$, it was found that the wicking powder adhered to the surface of the compact and a shape distortion was noted as shown in Fig. 3. In addition, at these high debinding temperatures $\left(200{ }^{\circ} \mathrm{C}\right)$, the rate of binder evaporation and removal may be higher than that of the capacity of the capillary system formed in the compact. Increasing of the binder removal resulted in decreasing of the cohesion of the samples which led to the observed shape distortion. By comparing Fig. 1 and Fig. 3, it could be concluded that debinding temperature of $160{ }^{\circ} \mathrm{C}$ is suitable for carrying out the debinding process; on the other hand, a debinding temperature of $200{ }^{\circ} \mathrm{C}$ could be excluded.

The effect of the wicking powder $\left(\mathrm{Al}_{2} \mathrm{O}_{3}\right)$ sizes on the percentage of binder weight loss after debinding process for $\mathrm{FeOX}, \mathrm{Ni}_{3} \mathrm{Al}$, and 316L are shown in Fig. 4, where it is revealed that the binder weight loss increased rapidly by increasing the debinding time and reached a constant value at 9 hours, approximately, for the different alloys. A trait that persists in Fig. 4a-to-c, is the presence of weight-loss stages. The first stage showed high weight loss occurring at debinding time ranging from 5-up to-9 hours; which could result from the binder water evaporation. 


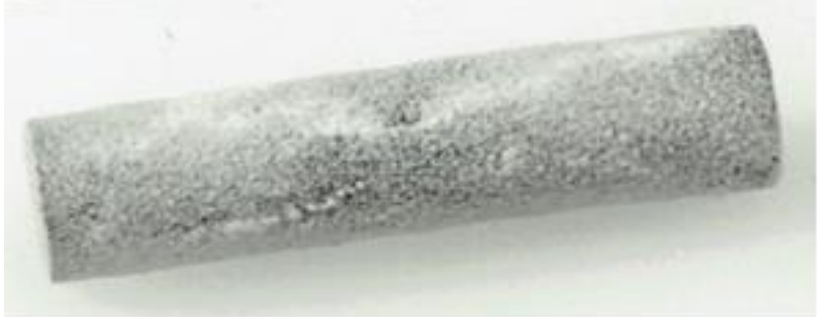

(A)

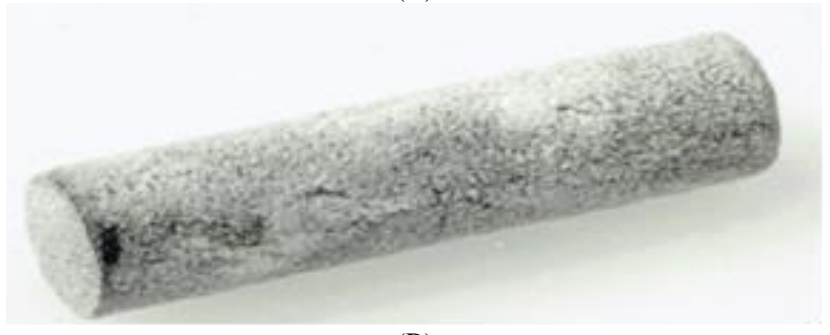

(B)

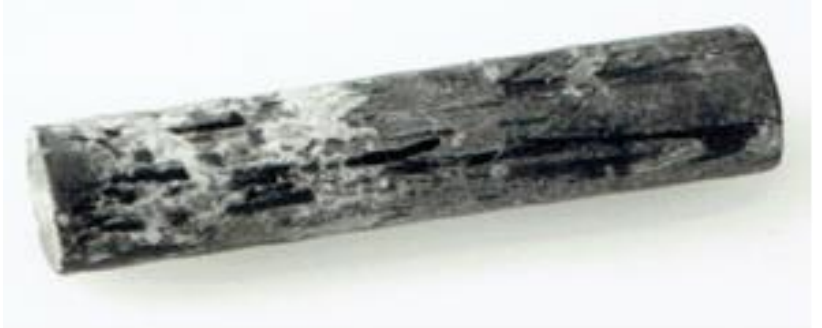

(C)

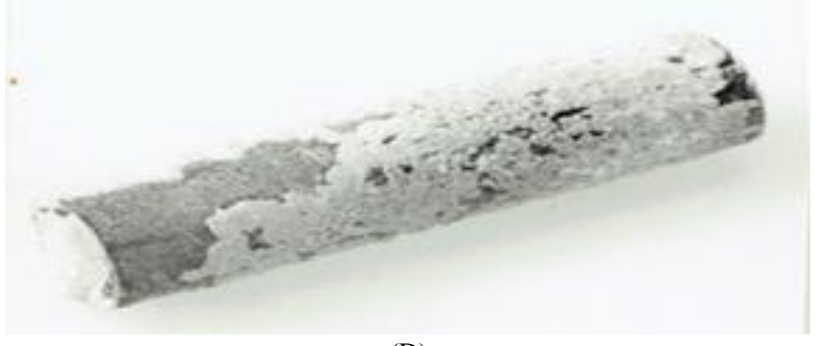

(D)

Fig. 1: The Effect of Alumina Particle Size and Debinding Time on the Adherence of $\mathrm{Al}_{2} \mathrm{O}_{3}$ on FeOX Surface at $160{ }^{\circ} \mathrm{C}$ for a Time of 3 (A, C) and $9 \mathrm{~h}(\mathrm{~B}, \mathrm{D})$ Using Alumina Size of 0.3 (A, B) and $<10 \mu \mathrm{m}(\mathrm{C}, \mathrm{D})$.

The maximum weight loss during this stage was recorded for FeOX alloy (Fig. 4a) at alumina with particle size of $1 \mu \mathrm{m}$, and for $\mathrm{Ni3Al}$ and 316L (Fig. 4b and c, respectively) at alumina with particle sizes of $2.5-3.5 \mu \mathrm{m}$. On the other hand, very fine alumina $(0.3$ $\mu \mathrm{m})$ or coarse alumina $(<30$ or $50-30 \mu \mathrm{m})$ showed much fewer amount of binder removal. The second stage showed a lower weight loss, which could be attributed to the decomposition of the remaining components with a higher molecular mass. This stage occurs after a debinding time of 9 hours, in which the binder removal rate is being slightly increased and reaches almost a constant value.

Thermal debinding has an interesting mechanism of actions which start with heating moulded parts to allow the binder components of low-temperature to decompose; subsequently, binder viscosity decreases and turns out to resemble fluid with the temperature increase. Meanwhile, a built up pressure is formed in the center region of the part, resulted from gas decomposition, obliging fluid to surface which would make this region washed-out from binder. In this case, the lack of binder movement control would lead to non-constrained particles, due to the decrease in the solid percentages at the surfaces, and a layer rich of binder could be formed consequently, after debinding. In addition, other phenomena could occur such as the outward flow, where the binder sometimes; as a result of the high negative capillary pressure at these areas, tend to sweeps and fills all the contacts and fine pores [5]. The final stage-

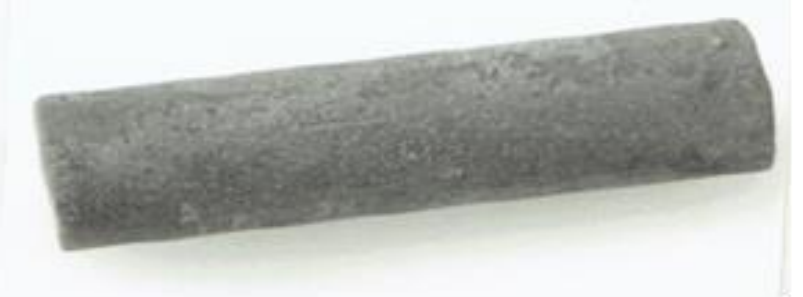

(A)

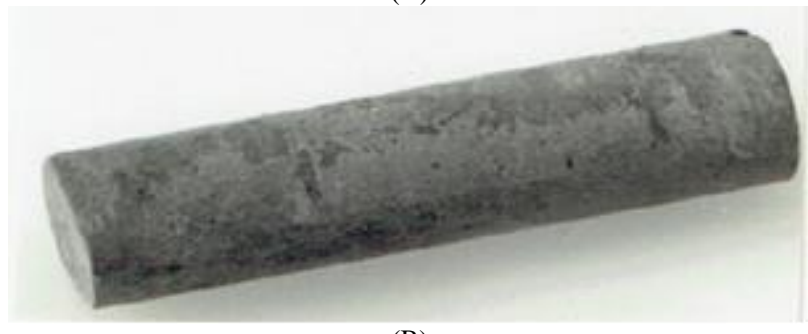

(B)

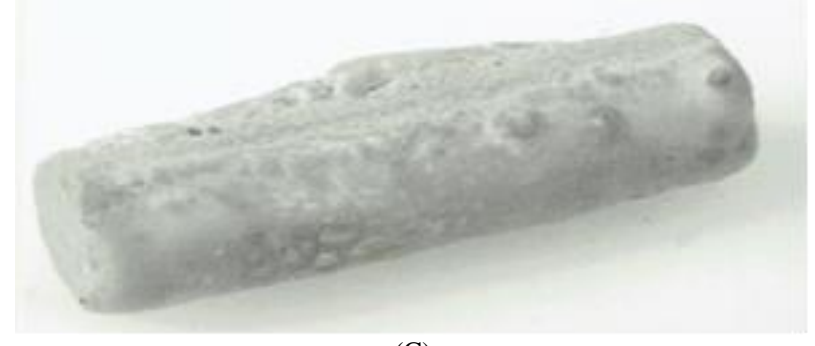

(C)

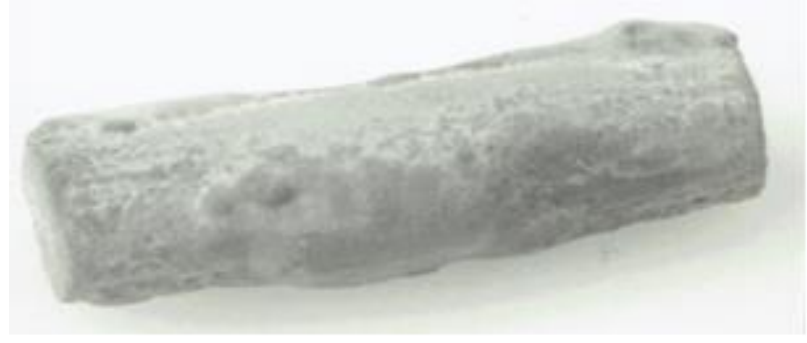

(D)

Fig. 2: The Effect of Alumina Particle Size and Debinding Time on the Adherence of $\mathrm{Al}_{2} \mathrm{O}_{3}$ on $316 \mathrm{~L}$ Surface at $160^{\circ} \mathrm{C}$ for a Time of $3(\mathrm{~A}, \mathrm{C})$ and 9h (B, D) Using Alumina Size of 0.3 (A, B) and <10 $\mu \mathrm{m}(\mathrm{C}, \mathrm{D})$.

of the process is reached when binder decomposition occurs at the outer edges, which would lead to an increase of volume in large inter-particle pores; at the same time, another binder decomposition takes place at inter-particle contacts and fine pores, resulting in a somewhat smaller mean pore size.

Debinding coefficient could be augmented with the adoption of elevated temperature, where molecular vibrations are stimulated. During the first stage, the control of the debinding process was carried out by the dissolution of binder at the debinding interface, agreeing with debinding dynamic analysis; consequently, control was transferred to the diffusion of binder in the connected pores of the outer layer in debinding state, with the increase in the debinding depth [11]. However, an adequately extended debinding period was essential due to the prerequisite of the following thermal debinding, which could only be done when an enough quantity of binder was solvent in the debinding state for the formation of connected pore nets in the green body.

Generally, the defects generated in the debinding processing cannot be well eliminated in the post processing. Therefore, the careful design of the debinding processing, to avoid the occurrence of defects, is of great importance. The relation between binder rate removal and debinding time for the different alloys at $160{ }^{\circ} \mathrm{C}$, using different particle sizes of alumina, are shown in Fig. 5, where it could be realized that the debinding rate of $\mathrm{FeOX}$ alloys has increased by decreasing the pore particle size of the wick powder, which resulted in a greater capillary attraction by the wick. Similar trend was observed for the $\mathrm{Ni}_{3} \mathrm{Al}$ and $316 \mathrm{~L}$ alloys. 


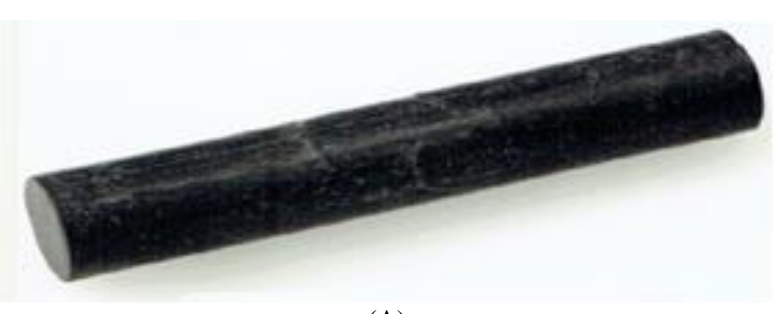

(A)

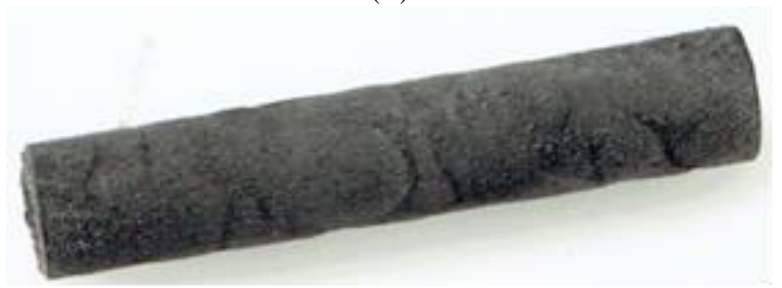

(B)

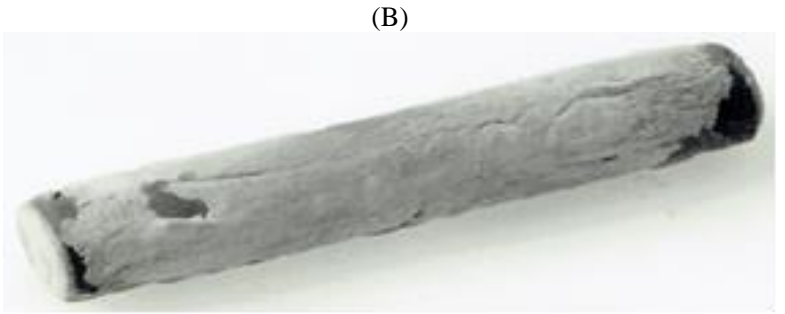

(C)

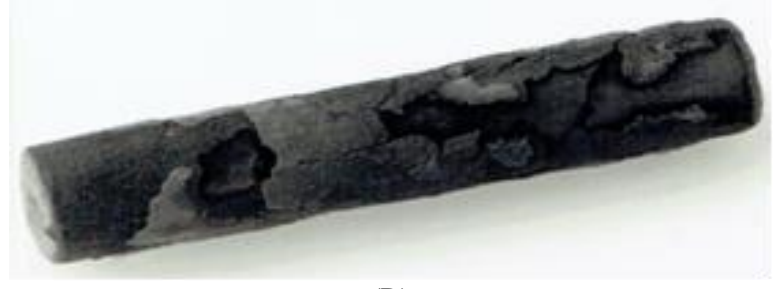

(D)

Fig. 3: The Effect of Alumina Particle Size and Debinding Time on the Adherence of $\mathrm{Al}_{2} \mathrm{O}_{3}$ on FeOX Surface at $200{ }^{\circ} \mathrm{C}$ for a Time of $9(\mathrm{~A}, \mathrm{C})$ and $27 \mathrm{~h}(\mathrm{~B}, \mathrm{D})$ Using Alumina Size of 1 (A, B) and $<30 \mu \mathrm{m}(\mathrm{C}, \mathrm{D})$.

It could be inferred that the removal rate is significantly increased with the increase of debinding time. In which more than $50 \%$ of the binder weight might be removed at the debinding time of 5 hours for $316 \mathrm{~L}$ powder using $1 \mu \mathrm{m}$ and $2.5-3.5 \mu \mathrm{m}$ wick powder, which agrees with the results found in literature [21]. A similar trend was observed for $\mathrm{FeOX}$ and $\mathrm{Ni}_{3} \mathrm{Al}$ alloys, where it was found that that the continuous increase of debinding time resulted in a slight increase in the removal rate. This could be attributed to the intercoupling of debinding time and the concentration of binders in the moulded compacts. In addition, the debinding rate showed a continuous decrease with time, in all performed experiments, which could be partially explained by the decrease in pressure head with time.

A representation for debinding by melt wicking could be made as a competition between the capillary forces due to the pores in the wick powder $\left(\mathrm{Al}_{2} \mathrm{O}_{3}\right)$ and the pores in the sample. As the material powder size is increased, the capillary force decreases; consequently, debinding occurs at a faster rate [22]. The addition of large particles to a small particle matrix would augment the green density of a powder mixture. The prediction of green density variation with composition requires information on the fractional packing density for the large and small powders, the mixture homogeneity, and the particle size ratio [23].

\section{Conclusion}

An investigation had been made about the influence of process variables on the debinding of injection moulded pieces by melt wicking. $\mathrm{FeOX}, \mathrm{Ni} 3 \mathrm{Al}$, and $316 \mathrm{~L}$ are the powders included in this study. The following conclusions could be drawn from this work:

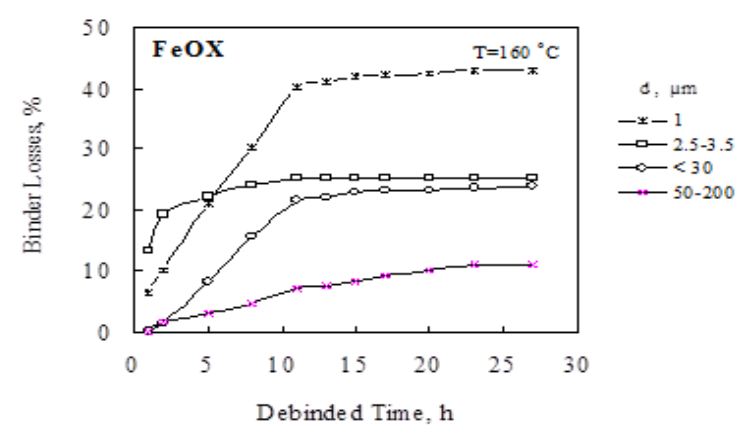

(A)

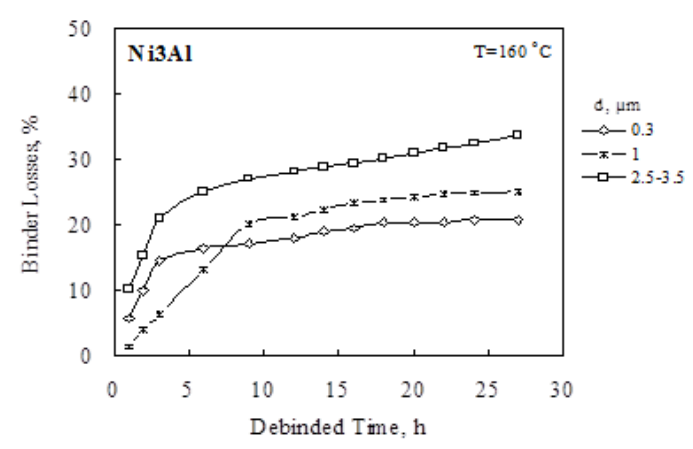

(B)

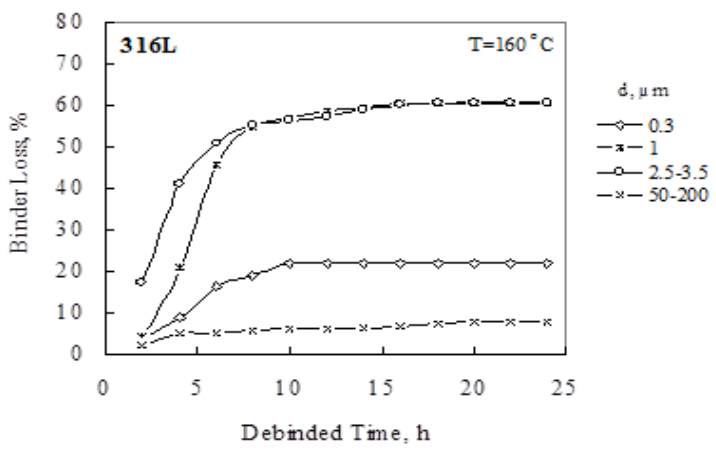

(C)

Fig. 4: The Relation between Debinding Time and the Binder Weight Loss Percent after Debinding Process at $160{ }^{\circ} \mathrm{C}$ for (A) $\mathrm{FeOX}$, (B) $\mathrm{Ni}_{3} \mathrm{Al}$, and (C) 316L Alloy Using Different Particle Size of Wicking Alumina Powder.

1) The increase of debinding time or the decrease in the particle size of alumina resulted in increasing the thickness of the adhered layer of alumina.

2) When the wicking powder is very small $(0.3 \mu \mathrm{m})$ or has a wide particle size range $(<10 \mu \mathrm{m})$, it becomes denser and its debinding efficiency is decreased.

3) At high debinding temperatures $\left(200^{\circ} \mathrm{C}\right)$, the rate of binder evaporation and removal increased, which lead to a decrease in the cohesion of samples resulting in a shape distortion.

4) The binder weight losses increased rapidly by increasing the debinding time and reached a constant value approximately at 9 hours.

5) The time required to achieve $50 \%$ of the debinding process for $316 \mathrm{~L}$ powders was 5 hours.

\section{Acknowledgement}

The authors would like to thank the Institute of Applied Materials Research (IAW) in Aachen, Germany, for financial and experimental support. 


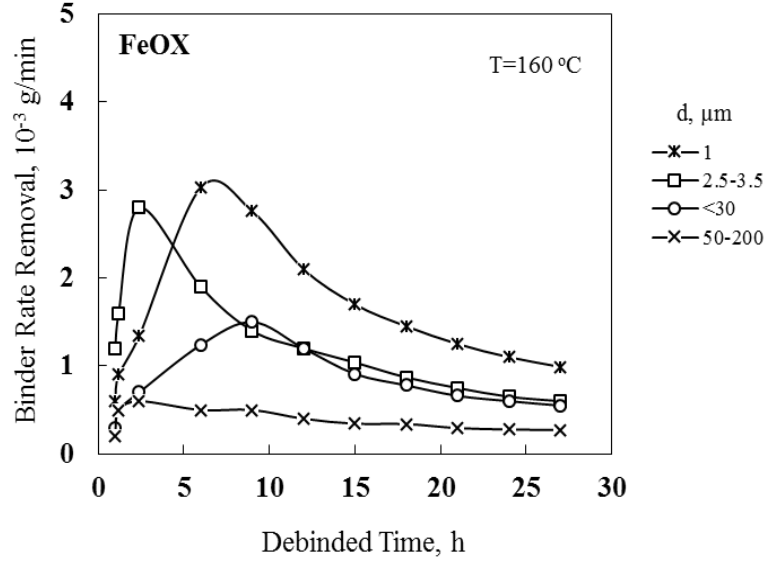

(A)

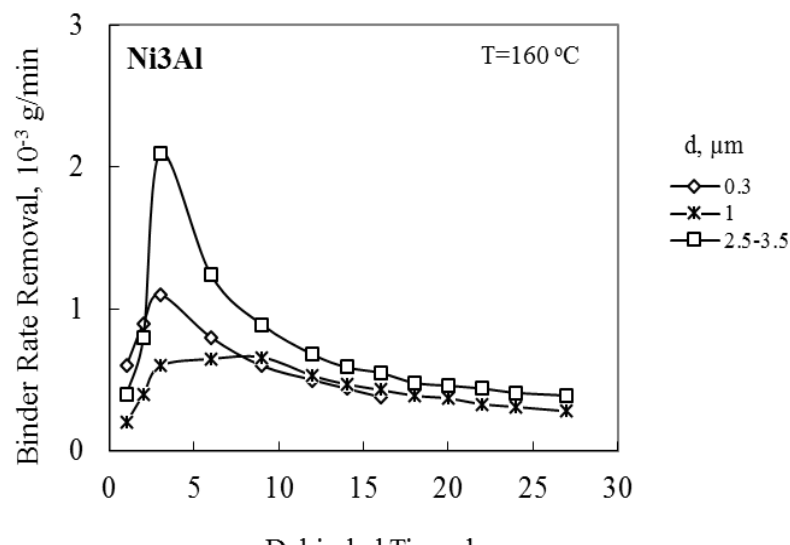

(B)

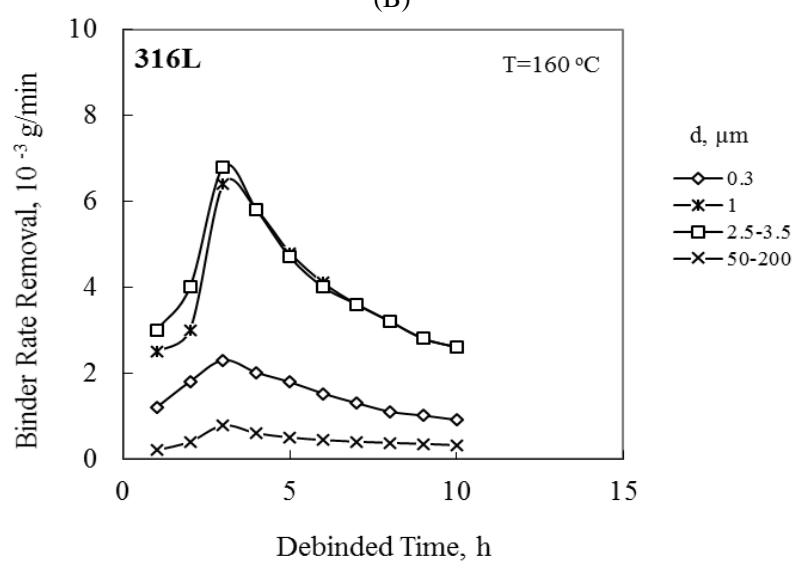

(C)

Fig. 5: The Relation between Debinding Time and Binder Rate Remova after Debinding Process at $160{ }^{\circ} \mathrm{C}$ for (A) FeOX, (B) $\mathrm{Ni}_{3} \mathrm{Al}$, and (C) 316L Alloy Using Different Particle Size of Wicking Alumina Powder.

\section{References}

[1] D.W. Park, D.H. Kim, H.S. Kim, Y.S. Kwon, K.K. Cho, S.G. Lim, and I..S. Ahn," A study of the debinding and sintering behavior of T42 high-speed steel produced by powder injection molding (PIM)", Res Chem Intermed (40), 2014, pp 2415-2421.

[2] M. Randall German; "Theory of Thermal Debinding", The International Journal of Powder Metallurgy, Vol. 23, No. 4, 1987, pp. $237-$ 245.

[3] C. Wang, Z. Lu, and K. Zhang," Evaluation of thermal debinding of injection-molded boron carbide in an ambient atmosphere", Int $\mathrm{J}$ Adv. Manuf. Technol. (64), 2013, pp 1751-1757.

[4] J. Rajabi, N. Muhamad, and A. Bakar Sulong," Effect of nano-sized powders on powder injection molding: a review", Microsyst Technol (18), 2012, pp 1941-1961.
[5] K.S. Hwang and Y.M. Hsieh," Comparative Study of Pore Structure Evolution During Solvent and Thermal Debinding of Powder Injection Molded Parts", Metallurgical and Materials Transactions A Vol. 27A, 1996, pp 245-253. http://dx.doi.org/10.1007/BF02648403.

[6] E. Hryha, H. Borgstrom, K. Sterky, and L. Nyborg," Influence of the steel powder type and processing parameters on the debinding of PM compacts with gelatin binder", J Therm Anal Calorim (118), 2014, pp 695-704.

[7] D. Lin, S.T. Chung, Y. S. Kwon, and S.J. Park," Preparation of Ti6Al-4V feedstock for titanium powder injection molding”, Journal of Mechanical Science and Technology 30 (4), 2016, pp 1859 1864. http://dx.doi.org/10.1007/s12206-016-0343-y.

[8] H. Miura, T. Osada, and Y Itoh,” Metal Injection Molding (MIM) Processing", Advances in Metallic Biomaterials, 2015, pp 27-56. http://dx.doi.org/10.1007/978-3-662-46842-5_2.

[9] B. Hausnerova, Ivo Kuritka, and D. Bleyan," Polyolefin Backbone Substitution in Binders for Low Temperature Powder Injection Moulding Feedstocks", Molecules (19), 2014, pp 2748-2760.

[10] Xin-lei Ni, Hai-qing Yin, L. Liu, Shan-jie Yi, and Xuan-hui Qu," Injection molding and debinding of micro gears fabricated by micro powder injection molding", International Journal of Minerals, Metallurgy and Materials Vol. 20, No. 1, 2013, PP 82-87.

[11] Xian-feng Yang, Jiang-hong Yang, Xie-wen Xu, Qi-cheng Liu, Zhi-peng Xie, and Wei Liu," Injection molding of ultra-fine Si3N4 powder for gas-pressure sintering", International Journal of Minerals, Metallurgy and Materials Vol. 22, No. 6, 2015, pp 654-659. http://dx.doi.org/10.1007/s12613-015-1119-6.

[12] A. Ruh, V. Piotter, K. Plewa, HG. Ritzhaupt-Kleiss, and J. Haußel,'Studies on Size Accuracy of Microgear Wheels Produced by Powder Injection Molding of Zirconia Feedstocks". Int J Adv. Manuf. Technol. (58), 2012, pp 1051-1059.

[13] A. Skalski, D. Bialo," Accuracy of the Parts from Iron Powder Manufactured by Injection Moulding", Advances in Intelligent Systems and Computing 393, 2016, pp 261-266. http://dx.doi.org/10.1007/978-3-319-23923-1_39.

[14] W. Diehl, H.P. Buchkremer, D. Stover; "Injection Molded Super alloy Parts Containerless HIP'ed", Conference Proceedings of: PM Aerospace Materials, 1987.

[15] M. Randall; "Powder Injection Molding", German Publisher: Meta Powder Industries Federation, 1990, pp. 95-114.

[16] R. Enneti, S.J. Park, R.M. German, and S.V. Atre," In Situ Characterization of Strength and Distortion during Powder Metal Processing", JOM, Vol. 64, No. 1, 2012, pp 28-34. http://dx.doi.org/10.1007/s11837-011-0232-x.

[17] M. Sahli \& J.-C. Gelin," Development of a feedstock formulation based on polypropylene for micro-powder soft embossing process of $316 \mathrm{~L}$ stainless steel micro-channel part", Int J Adv. Manuf. Technol. (69), 2013, pp 2139-2148.

[18] A. Johnsson, E. Carlstrom, L. Hermansson and R. Carlsson; "RateControlled Extraction Unit for Removal of Organic Binders from Injection Molded Ceramics", Ceramic Powders, P.Vincenzini (ed.), Elsevier Scientific, Amsterdam, Nether Lands, 1983, pp. 767-772.

[19] J. Rajabi, N. Muhamad, and A. Bakar Sulong," Effect of nano-sized powders on powder injection molding: a review", Microsyst Technol (18), 2012, pp 1941-1961.

[20] 19.Zi-wei Xu, Cheng-chang Jia, Chun-jiang Kuang, and Xuan-hui Qu," Fabrication and sintering behavior of high-nitrogen nickel-free stainless steels by metal injection molding", International Journal of Minerals, Metallurgy and Materials Vol. 17, No. 4, 2010, pp 223 228.

[21] T.S. Wei and R.M. German, Two-stage Fast Debinding of Injection Molding Powder Compacts, US Patent, Appl. 5028367, 1991.

[22] C.S. Aria and B.R. Patterson; "Influence of Process Variables on Debinding by Melt Wicking", MPIF, APMI, 1984, Vol. 15, pp. 403-416.

[23] R.M. German; "Prediction of Sintered Density for Bimodal Powder Mixture", Metallurgical Transactions A, Vol. 23A, May 1992, pp. 1455-1465. http://dx.doi.org/10.1007/BF02647329. 